\title{
HEAT TRANSFER CHARACTERISTICS FOR A FIN EXPOSED TO FULLY WET
}

\section{AIR}

\author{
ZIAD M. AL-MAKHYOUL \& MAHIR HASHIM HADI
}

Department of Mechanical Engineering, University of Mosul, Iraq

\begin{abstract}
A numerical method for two types of longitudinal tapered fins exposed to fully wet air conditions have been studied using grid generation methods. The study included the effect of relative humidity on the temperature distribution for a fully dry fin and fully wet fin at different relative humidity of 0, 50, 75 and 100\%. Fin effectiveness, fin efficiency and heat flow have been calculated at a relative humidity of 10, 20, 30, 40, 50 and 100\% and fin length varies from 0.01 to $0.1 \mathrm{~m}$. This study shows that the fin efficiency and fin effectiveness in dry fin are found to be larger than those in the wet fin and the temperature gradient at the tip of a ful006Cy wet fin is smaller than that in the dry fin.
\end{abstract}

KEY WORDS: Numerical Analysis, Longitudinal Tapered Fins \& Fully Wet Air

Received: Aug 15, 2019; Accepted: Aug 30, 2019; Published: Sep 14, 2019; Paper Id.: IJMPERDOCT201929

\section{NOMENCLATURE}

\begin{tabular}{|c|c|}
\hline A & Fin surface area \\
\hline $\mathrm{Cp}$ & Specific heat of moist air \\
\hline $\mathrm{H}$ & Heat transfer coefficient \\
\hline Hfg & Latent heat of condensation $(\mathrm{hfg}=2430)$ \\
\hline $\mathrm{Hm}$ & Mass transfer coefficient \\
\hline $\mathrm{H}$ & Fin whdth \\
\hline $\mathrm{K}$ & Thermal conductivity for the fin (copper material, $\mathrm{k}=400$ ) \\
\hline Le & Lewis number \\
\hline $\mathrm{Lf}$ & Length of fin \\
\hline $\mathrm{M}, \mathrm{N}$ & Number of grid in longitudinal and transverse directions \\
\hline Patm & Atmospheric pressure \\
\hline Ps & Pressure at saturated temperature \\
\hline $\mathrm{Pv}$ & Water vapour pressure \\
\hline QFn & Heat transfer from fin numerically \\
\hline QFMAX & Maximum heat transfer \\
\hline QNF & Heat transfer at the base without fin \\
\hline $\mathrm{Wi}$ & Inner thickness of fin \\
\hline Wo & Outer thickness of fin \\
\hline RH & Relative humidity \\
\hline Ts & Surface temperature of fin \\
\hline $\mathrm{Tb}$ & Base temperature of fin $\left(2^{\circ} \mathrm{C}\right)$ \\
\hline $\mathrm{Tf}$ & Fluid temperature $\left(30^{\circ} \mathrm{C}\right)$ \\
\hline $\mathrm{X}$ & Horizontal direction \\
\hline Y & Vertical direction \\
\hline$\varepsilon$ & Fin effectiveness \\
\hline$\eta f$ & Fin efficiency \\
\hline$\theta$ & Dimensionless local fin surface temperature (Tf-Ts)/(Tf-Tb) \\
\hline$\omega f$ & Humidity ratio of air \\
\hline$\omega \mathrm{s}$ & Humidity ratio of fin surface \\
\hline$\beta$ & Parameter defined as hfg/ (cp*Le2/3) \\
\hline
\end{tabular}

$\mathrm{m}^{2}$
$\mathrm{~kJ} /\left(\mathrm{kg} .{ }^{\circ} \mathrm{K}\right)$
$\mathrm{W} /\left(\mathrm{m}^{2} .{ }^{\circ} \mathrm{K}\right)$
$\mathrm{kJ} / \mathrm{kg}$
$\mathrm{W} / \mathrm{m}^{2} .{ }^{\circ} \mathrm{K}$
$\mathrm{m}$
$\mathrm{W} / \mathrm{m} .{ }^{\circ} \mathrm{K}$
-----
$\mathrm{m}$
-----
$\mathrm{Bar}$
$\mathrm{Bar}$
$\mathrm{Bar}$
$\mathrm{W}$
$\mathrm{W}$
$\mathrm{W}$
$\mathrm{M}$
$\mathrm{M}$
$\%$
${ }^{\circ} \mathrm{C}$
${ }^{\circ} \mathrm{C}$
${ }^{\circ} \mathrm{C}$
$\mathrm{kgv} / \mathrm{kga}$
$\mathrm{kgv} / \mathrm{kga}$
${ }^{\circ} \mathrm{K}$




\section{INTRODUCTION}

Finned tubes are used in many applications like, air conditioning, refrigeration, motors and heat exchanger systems. The wet conditions processes occur when the surface coil temperature is less than the dew point temperature of the air (Sharqawy and Zubair, 2008).

Several researchers have studied the effect of wet air on the performance of extended surfaces. The first study was presented from Rosario and Rahman (1989). They showed the radial fin assembly exposed to the fully wet conditions and assumed a fixed sensible to the total heat ratio. Their results showed that their relationship between the fin characteristics and properties of air under wet conditions.

Wu and Bong (1994) studied analytically the effect of wet air condition on the longitudinal fin (fully and partially) wetted air depending on variable relative humidity. The results showing not much effect on the fin efficiency with relative humidity.

Liang et al. (2000) studied the fin efficiency for one- and two-dimensional plate fin under wet condition using finite difference technique. Their results showed the agreement in results between one- and two-dimensional model and the wet conditions of air is more effected on fin efficiency.

Kundu (2002) investigated the fin performances of longitudinal wet fins of variable shapes analytically. $\mathrm{He}$ is studying the effect of dehumidification when the wet air coming to coil surface temperature and found the fin efficiency with linear relationship may be associated with an erroneous prediction.

Kundu and Das (2004) studied analytically the effect of wet conditions to the longitudinal and spine fins under dry and fully wet conditions. They proved the linear relationship between the temperature and relative humidity by solving differential equation mathematically depending on Frobenius power series.

Naphon (2006) theoretically investigated the temperature distribution for the annular fin of constant thickness exposed to dry and partially wet air. The study included mathematical models based on the equations of conservation, energy and mass are solved by finite difference technique to obtain the temperature distribution along the fin. His results were agreed with other researchers.

Sharqawy and Zubair (2007) studied the performance of one-dimensional heat transfer for longitudinal fin analytically. The study included heat and mass transfer. The analysis of one-dimensional of annular fins of constant thickness. The results were a good agreement with the numerical investigated for Sharqawy and Zubair (2008).

Kundu and Barman (2010) studied the fin efficiency and temperature distribution for one-dimensional annular fin rectangular shape using numerical analysis. They used equation including the relationship between temperature and relative humidity. The mass transfer effect on the analysis of wet fin was used in this study.

Ziad (2014) studied the performance of longitudinal fin constant thickness exposed to the wet air conditions using finite difference technique. The temperature distribution on the surface of the fin was founded using three-degree polynomial equation for the relationship between relative humidity and temperature at relative humidity from 0 to $100 \%$ and fin length from 0.01 to $0.1 \mathrm{~m}$. Also, fin effectiveness and efficiency and heat transfer have been studied. The study showed that the fin effectiveness and fin efficiency when the fin surface is dry bigger than those in the wet fin and the temperature gradient at the tip for a wet fin is smaller than that for the dry fin. 
The effect of relative humidity on characteristics of heat transfer like the fin efficiency, fin effectiveness, temperature distribution and barometric pressure for two types of longitudinal tapered fins will be studied numerically in this study.

\section{ANALYSIS}

The case of steady state heat transfer is carried out for two types of longitudinal tapered fins under wet air conditions is shown in figure below.

There are some assumptions which used in this study to simplify the analysis, the assumptions are:

- Constant thermal conductivity for fin.

- Constant relative humidity, pressure and temperature for the surrounding air.

- Constant base temperature.

- Neglected the pressure drop of air effect due flow of air.

- Steady state heat flow through the fin.

- No heat source in the fin.

- Constant heat and mass transfer.

The fin surface can be divided to two cases, fully dry fin surface and fully wet fin surface. Fully dry fin surface represents the temperatures over the entire surface of the fin are larger than the dew point temperature of the air surrounding and this case is not humidification occurs while the fin surface is called fully wet fin when the temperatures above the entire fin surface are smaller than the dew point temperature of the surrounding air, the heat and mass transfer was occurred (Kundu, 2002). In this study, the temperature over the entire surface of fin is assumed under the dew point temperature of the air surrounding.

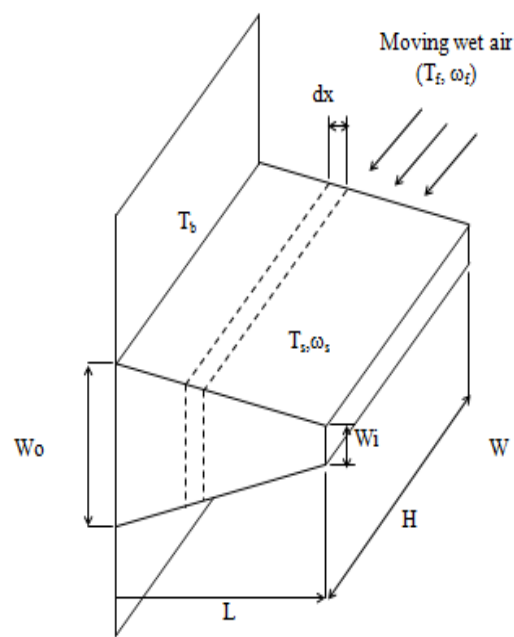

(a)

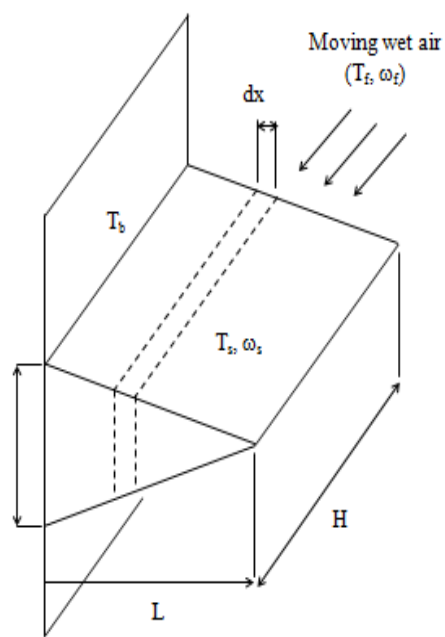

(b)

Figure 1: Schematic Diagram of Longitudinal Tapered Fins (a) Trapezoidal Section and (b) Triangular Section Under Wet Air. 


\section{THE NUMERICAL APPROACH}

From the heat conduction equation in (1) for longitudinal tapered fin using grid generation method to solve the irregular mesh in the problem. The physical coordinate $(x, y)$ is converted to coordinate $(\xi, \eta)$. Each interval between any two points $\Delta \xi$ and $\Delta \eta$ is equal 1.0 .

$$
\frac{\partial^{2} T}{\partial x^{2}}+\frac{\partial^{2} T}{\partial y^{2}}=0.0
$$

Every part of equation (1) can be written as a function of $(\xi, \eta)$ coordinate (Ziad, 2014):

$$
\begin{aligned}
& \frac{\partial \mathrm{T}}{\partial \mathrm{x}}=\frac{\partial \mathrm{T}}{\partial \xi} * \frac{\partial \xi}{\partial \mathrm{x}}+\frac{\partial \mathrm{T}}{\partial \eta} * \frac{\partial \eta}{\partial \mathrm{x}} \\
& \frac{\partial \mathrm{T}}{\partial \mathrm{y}}=\frac{\partial \mathrm{T}}{\partial \xi} * \frac{\partial \xi}{\partial \mathrm{y}}+\frac{\partial \mathrm{T}}{\partial \eta} * \frac{\partial \eta}{\partial \mathrm{y}} \\
& \mathrm{z}=0.5\left[\frac{(\mathrm{wi}-\mathrm{wo}) * \mathrm{x}}{\mathrm{L}_{\mathrm{f}}}+\mathrm{wo}\right]
\end{aligned}
$$

When: Wo $>$ Wi $>0.0$ for fin (a) and Wo=0.0 for fin (b)

$$
\begin{aligned}
& \frac{\partial^{2} \mathrm{~T}}{\partial \mathrm{x}^{2}}=\left(\frac{\partial \mathrm{T}}{\partial \xi} * \frac{\partial^{2} \xi}{\partial \mathrm{x}^{2}}\right)+\left(\frac{\partial \mathrm{T}}{\partial \eta} * \frac{\partial^{2} \eta}{\partial \mathrm{x}^{2}}\right)+\left(\frac{\partial^{2} \mathrm{~T}}{\partial \xi^{2}}\right)\left(\frac{\partial \xi}{\partial \mathrm{x}}\right)^{2}+\left(\frac{\partial^{2} \mathrm{~T}}{\partial \eta^{2}}\right)\left(\frac{\partial \eta}{\partial \mathrm{x}}\right)^{2}+2\left(\frac{\partial^{2} \mathrm{~T}}{\partial \eta \partial \xi}\right)\left(\frac{\partial \eta}{\partial \mathrm{x}}\right)\left(\frac{\partial \xi}{\partial \mathrm{x}}\right) \\
& \frac{\partial^{2} \mathrm{~T}}{\partial \mathrm{y}^{2}}=\left(\frac{\partial \mathrm{T}}{\partial \xi} * \frac{\partial^{2} \xi}{\partial \mathrm{y}^{2}}\right)+\left(\frac{\partial \mathrm{T}}{\partial \eta} * \frac{\partial^{2} \eta}{\partial \mathrm{y}^{2}}\right)+\left(\frac{\partial^{2} \mathrm{~T}}{\partial \xi^{2}}\right)\left(\frac{\partial \xi}{\partial \mathrm{y}}\right)^{2}+\left(\frac{\partial^{2} \mathrm{~T}}{\partial \eta^{2}}\right)\left(\frac{\partial \eta}{\partial \mathrm{y}}\right)^{2}+2\left(\frac{\partial^{2} \mathrm{~T}}{\partial \eta \partial \xi}\right)\left(\frac{\partial \eta}{\partial \mathrm{y}}\right)\left(\frac{\partial \xi}{\partial \mathrm{y}}\right)
\end{aligned}
$$

The derivatives $\frac{\partial \mathrm{T}}{\partial \xi}, \frac{\partial \mathrm{T}}{\partial \eta}, \frac{\partial^{2} \mathrm{~T}}{\partial \eta^{2}}, \frac{\partial^{2} \mathrm{~T}}{\partial \xi^{2}}$ and $\frac{\partial^{2} \mathrm{~T}}{\partial \xi \partial \eta}$ are representing the central difference for Tylor series respect to $\eta, \xi$ as:

$$
\begin{aligned}
& \left(\frac{\partial T}{\partial x}\right)=\frac{T(i+1, j)-T(i-1, j)}{2 \Delta x} \text { and }\left(\frac{\partial T}{\partial y}\right)=\frac{T(i, j+1)-T(i, j+1)}{2 \Delta y} \\
& \left(\frac{\partial^{2} T}{\partial x^{2}}\right)=\frac{T(i+1, j)-2 T(i, j)+T(i-1, j)}{(\Delta x)^{2}} \text { and }\left(\frac{\partial^{2} T}{\partial z^{2}}\right)=\frac{T(i, j+1)-2 T(i, j)+T(i, j-1)}{(\Delta z)^{2}} \\
& \left(\frac{\partial^{2} T}{\partial x \partial y}\right)=\frac{T(i+1, j+1)-T(i-1, j+1)-T(i+1, j-1)+T(i-1, j-1)}{4 \Delta x \Delta y}
\end{aligned}
$$

After substituting and simplifying the above equations, the temperature distribution in the interior points is:

$$
T(i, j)=\frac{A T(i-1, j)+B T(i+1, j)+C T(i, j-1)+D T(i, j+1)+E}{A+B+C+D}
$$

When:

$$
\begin{aligned}
& \mathrm{A}=\left(\frac{\partial \xi}{\partial \mathrm{x}}\right)^{2}+\left(\frac{\partial \xi}{\partial \mathrm{y}}\right)-0.5 *\left(\left(\frac{\partial^{2} \xi}{\partial \mathrm{x}^{2}}\right)+\left(\frac{\partial^{2} \xi}{\partial \mathrm{y}^{2}}\right)\right)-\frac{0.5}{\mathrm{x}} *\left(\frac{\partial \xi}{\partial \mathrm{x}}\right) \\
& \mathrm{B}=\left(\frac{\partial \eta}{\partial \mathrm{x}}\right)^{2}+\left(\frac{\partial \eta}{\partial \mathrm{y}}\right)-0.5 *\left(\left(\frac{\partial^{2} \eta}{\partial \mathrm{x}^{2}}\right)+\left(\frac{\partial^{2} \eta}{\partial \mathrm{y}^{2}}\right)\right)-\frac{0.5}{\mathrm{x}} *\left(\frac{\partial \eta}{\partial \mathrm{x}}\right)
\end{aligned}
$$




$$
\begin{aligned}
& \mathrm{C}=\left(\frac{\partial \eta}{\partial \mathrm{x}}\right)^{2}+\left(\frac{\partial \eta}{\partial \mathrm{y}}\right)+0.5\left(\left(\frac{\partial^{2} \eta}{\partial \mathrm{x}^{2}}\right)+\left(\frac{\partial^{2} \eta}{\partial \mathrm{y}^{2}}\right)\right)+\frac{0.5}{\mathrm{x}} *\left(\frac{\partial \eta}{\partial \mathrm{x}}\right) \\
& \mathrm{D}=\left(\frac{\partial \xi}{\partial \mathrm{x}}\right)^{2}+\left(\frac{\partial \xi}{\partial \mathrm{y}}\right)+0.5 *\left(\left(\frac{\partial^{2 \xi}}{\partial \mathrm{x}^{2}}\right)+\left(\frac{\partial^{2 \xi}}{\partial \mathrm{y}^{2}}\right)\right)+\frac{0.5}{\mathrm{x}} *\left(\frac{\partial \xi}{\partial \mathrm{x}}\right) \\
& \mathrm{E}=2\left(\frac{\partial \xi}{\partial \mathrm{x}} \cdot \frac{\partial \eta}{\partial \mathrm{x}}+\frac{\partial \xi}{\partial \mathrm{y}} \cdot \frac{\partial \eta}{\partial \mathrm{y}}\right)\left(\frac{\partial^{2} \mathrm{~T}}{\partial \xi \partial \eta}\right)
\end{aligned}
$$

When $1<\mathrm{i}<\mathrm{N}$ and $1<\mathrm{j}<\mathrm{M}$

The boundary condition and temperature distribution in the center line of the fin is yielded as:

$$
\frac{\partial \mathrm{T}}{\partial \mathrm{y}}=0
$$

$\frac{\partial \mathrm{T}}{\partial \mathrm{y}}=\frac{\partial \mathrm{T}}{\partial \xi} \cdot \frac{\partial \xi}{\partial \mathrm{y}}+\frac{\partial \mathrm{T}}{\partial \eta} \cdot \frac{\partial \eta}{\partial \mathrm{y}}=0$

$\mathrm{T}(\mathrm{i}, 1)=\frac{1}{3}\left[\left(\mathrm{~T}(\mathrm{i}+1,1)-\mathrm{T}(\mathrm{i}-1,1) * \frac{\partial \xi}{\partial \mathrm{y}}+4 \mathrm{~T}(\mathrm{i}, 2)-\mathrm{T}(\mathrm{i}, 3) * \frac{\partial \eta}{\partial \mathrm{y}}\right)\right] \frac{1}{\frac{\partial \eta}{\partial y}}$

$\mathrm{T}_{\eta}$ and $\mathrm{r}_{\eta}$ are calculated for $\mathrm{T}, \mathrm{r}$ respect to $\eta$ as:

$\frac{\partial T}{\partial x}=\frac{4 T(i, j+1)-3 T(i, j)-T(i, j+2)}{2 \Delta x}$

The temperature distribution and boundary condition at the fin tip can be written as:

$\frac{\partial \mathrm{T}}{\partial \mathrm{x}}=0$

$\frac{\partial \mathrm{T}}{\partial \mathrm{x}}=\frac{\partial \mathrm{T}}{\partial \xi} \cdot \frac{\partial \xi}{\partial \mathrm{x}}+\frac{\partial \mathrm{T}}{\partial \eta} \cdot \frac{\partial \eta}{\partial \mathrm{x}}=0$

$T(N, j)=\frac{1}{3}\left[\left(4 T(N-1, j)-T(N-2, j)+T(N, j-1)-T(N, j+1) * \frac{\partial \eta}{\partial x}\right)\right] \frac{1}{\frac{\partial \xi}{\partial x}}$

$\mathrm{T}_{\xi}$ and $\mathrm{z}_{\xi}$ are calculated for $\mathrm{T}, \mathrm{z}$ respect to $\xi$ as:

$\frac{\partial T}{\partial x}=\frac{f(i-2, j)+3 f(i, j)-4 f(i-1, j)}{2 \Delta x}$

The specific humidity in the saturated case on the fin surface $\omega_{\mathrm{s}}$ can be calculated from the polynomial relationship by Kundu and Das (2004):

$\omega_{\mathrm{s}}=\left(3.744+0.307 \& \mathrm{~T}_{\mathrm{s}}+0.0046 \mathrm{~T}_{\mathrm{s}}^{2}+0.0004 \mathrm{~T}_{\mathrm{s}}^{3}\right) \times 10^{-3}$

when $0^{\circ} \mathrm{C}<\mathrm{T}_{\mathrm{f}}<30^{\circ} \mathrm{C}$ 
Depending on the Chilton-Colburn investigation (Sharqawy \& Zubair, 2007), the relation between the coefficient of mass transfer and coefficient of heat transfer is:

$$
\frac{\mathrm{h}}{\mathrm{h}_{\mathrm{m}}}=\mathrm{Cp} \times \mathrm{Le}^{\frac{2}{3}}
$$

The boundary condition at the fin surface is:

$$
-k \frac{\partial T}{\partial y}=h\left(T_{f}-T_{s}\right)+h_{f g} \cdot h_{m}\left(\omega_{f}-\omega_{s}\right)
$$

The evaporation latent heat, specific heat of air, Lewis number and $\mathrm{Cp}$ assumed are constant, therefore $\beta$ will be as a constant (Kundu \& Das, 2004; Kundu \& Barman, 2010; Sharqawy \& Zubair, 2007, 2008) and then the equation (23) will be as:

$$
\begin{aligned}
& -\mathrm{k} \frac{\partial \mathrm{T}}{\partial \mathrm{y}}=\mathrm{h}\left[\left(\mathrm{T}_{\mathrm{f}}-\mathrm{T}_{\mathrm{s}}\right)+\beta \times\left(\omega_{\mathrm{f}}-\omega_{\mathrm{s}}\right)\right] \\
& \omega_{\mathrm{f}}=0.622 \times \frac{\mathrm{P}_{\mathrm{v}}}{\mathrm{P}_{\mathrm{atm}}} \\
& \mathrm{P}_{\mathrm{v}}=\mathrm{RH} \times \mathrm{P}_{\mathrm{s}}
\end{aligned}
$$

Then,

$$
\omega_{\mathrm{f}}=0.622 \times \frac{\mathrm{P}_{\mathrm{s}} \times \mathrm{RH}}{\mathrm{P}_{\mathrm{atm}}}
$$

$\mathrm{P}_{\mathrm{v}}$ is the water vapour pressure of water, $\mathrm{P}_{\mathrm{atm}}$ is the barometric pressure, $\mathrm{RH}$ represents the relative humidity of air surrounding and $\mathrm{P}_{\mathrm{s}}$ is the pressure at saturated temperature.

$$
\mathrm{T}(\mathrm{i}, \mathrm{M})=\frac{\mathrm{A} 1 * \mathrm{~T}(\mathrm{i}-1, \mathrm{M})+\mathrm{B} 1 * \mathrm{~T}(\mathrm{i}+1, \mathrm{M})+\mathrm{Cl} * \mathrm{~T}(\mathrm{i}, \mathrm{M}-1)+\mathrm{D} 1\left(\mathrm{~T}_{\mathrm{f}}+\beta\left(\omega_{\mathrm{f}}-\omega(\mathrm{i}, \mathrm{M})\right)\right)}{\mathrm{E} 1}
$$

Where $\mathrm{A} 1, \mathrm{~B} 1$ and $\mathrm{C} 1$ are representing $\mathrm{kA} / \mathrm{dx}$ at the fin surface in each point around $\mathrm{T}(\mathrm{i}, \mathrm{j}) . \mathrm{C} 1$ is the conductance of heat (hA) between the surrounding and the fin surface.

$$
\mathrm{D} 1=\mathrm{A} 1+\mathrm{B} 1+\mathrm{C} 1+\mathrm{D} 1
$$

The temperature in the points at the corner is calculated as:

$$
\begin{aligned}
& \mathrm{T}(\mathrm{N}, 1)=(\mathrm{T}(\mathrm{N}-1,1)+\mathrm{T}(\mathrm{N}, 2)) / 2 \text { and } \mathrm{T}(\mathrm{N}, \mathrm{M})=(\mathrm{T}(\mathrm{N}-1, \mathrm{M})+\mathrm{T}(\mathrm{N}, \mathrm{M}-1)) / 2 \\
& \mathrm{QFn}=\sum_{\mathrm{i}=1}^{\mathrm{i}=\mathrm{N}} \mathrm{H} * \Delta \mathrm{x}(\mathrm{i}) * \mathrm{~h} *\left(\left(\mathrm{~T}_{\mathrm{f}}-\mathrm{T}(\mathrm{i}, \mathrm{j})+\beta *\left(\omega_{\mathrm{f}}-\omega(\mathrm{i}, \mathrm{M})\right)\right.\right. \\
& \mathrm{QF} \mathrm{MAX}=\sum_{\mathrm{i}=1}^{\mathrm{i}=\mathrm{N}} \mathrm{H} * \Delta \mathrm{x}(\mathrm{i}) * \mathrm{~h} *\left(\left(\mathrm{~T}_{\mathrm{f}}-\mathrm{T}(1,1)+\beta *\left(\omega_{\mathrm{f}}-\omega(1,1)\right)\right)\right. \\
& \mathrm{QNF}=\sum_{\mathrm{i}=1}^{\mathrm{i}=\mathrm{N}} \mathrm{H} *(\mathrm{wo}-\mathrm{wi}) * \mathrm{~h} *\left(\left(\mathrm{~T}_{\mathrm{f}}-\mathrm{T}(1,1)\right)\right.
\end{aligned}
$$

The fin effectiveness and fin efficiency can be written as: 


$$
\eta_{\mathrm{f}}=\frac{\mathrm{QF}_{\mathrm{n}}}{\mathrm{QF}_{\mathrm{MAX}}}, \varepsilon=\frac{\mathrm{QF}_{\mathrm{n}}}{\mathrm{QNF}}
$$

\section{THE RESULTS AND DISCUSSIONS}

In figure 3, the distribution of temperature on fin surface was drawn against the dimensionless fin length at $\mathrm{RH}=50,75$ and $100 \%$. At these three magnitudes of RH, the temperature at the tip of the fin is below the dew point temperature of the air, thus, this fin under fully wet. At the same position of the fin, the temperature of dimensionless $\theta$ is higher for a dry fin than for a wet fin. Therefore, the temperature at the surface of the fin increases when condensation is occurred. The higher RH means high temperature on the fin surface because the latent heat of vaporization and then the temperature gradient at the fin tip when the fin is dry higher than that the temperature gradient when the fin is wet.

Figure 3 shows the relation between the heat transfer and the fin length at different relative humidity of (10, 20, 30, 50 and 100) \%. When the relative humidity is constant, the increases in fin length causes increases in heat transfer because the increases in the temperature gradient. The bigger relative humidity leads to bigger heat transfer along the fin.

Figure 4 represents the relation between the fin efficiency and fin effectiveness against fin length for the two types of fins. The effectiveness of the fin increases but the efficiency of fin decreases within the length of fin because the increases in fin length causes increases in the temperature of the fin at the same reduces and then decreases in fin efficiency. However, the increases in fin length lead to increases in the actual heat transfer and then increases in the fin effectiveness. Generally, the increasing in the relative humidity at the same fin length makes decreases in the curve of efficiency and effectiveness comparing with dry fin.

Also, the figure $5(\mathrm{a}, \mathrm{b})$ shows the efficiency of the fin and effectiveness of fin against the relative humidity at 10 , $20,30,40,50$ and $100 \%$ at different fin length of $0.02,0.05$ and $0.08 \mathrm{~m}$.

Figure 6 is showing the effect of barometric pressure at different relative humidity of the fin efficiency and fin effectiveness. It is clear that the fin efficiency increases with increase in the barometric pressure. When the barometric pressure increase lead to increases in the humidity ratio. This case makes an increase in the mass transfer and then increase in the heat transfer because of condensation.

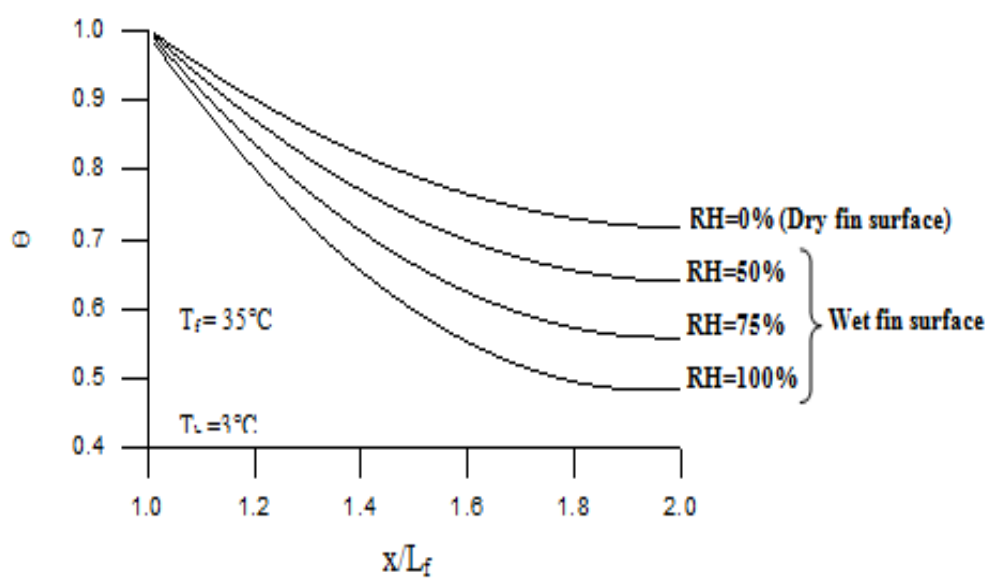

Figure 2: Temperature Distribution with Fin Length at Variable RH. 


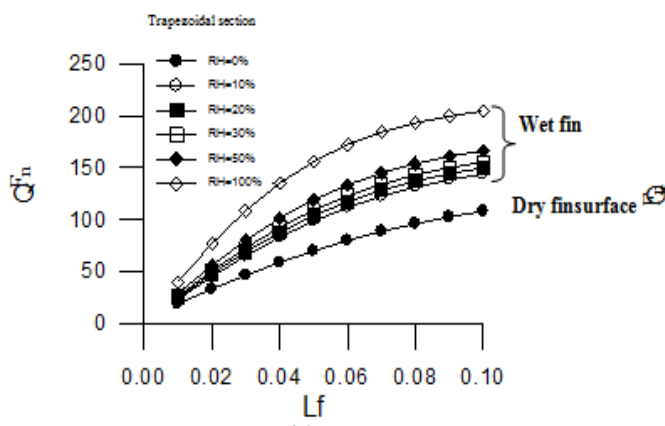

(a)

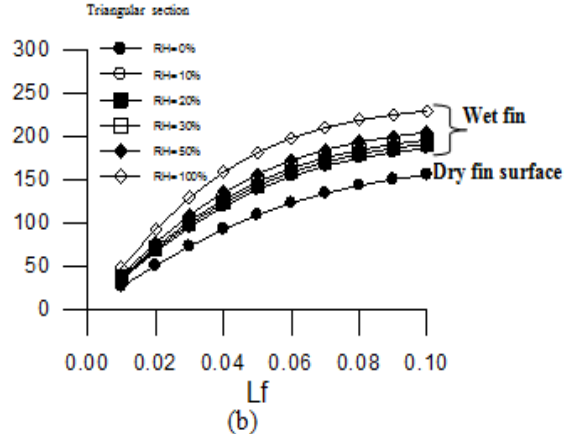

(b)

Figure 3: Heat Transfer Against Fin Length at Variable RH.
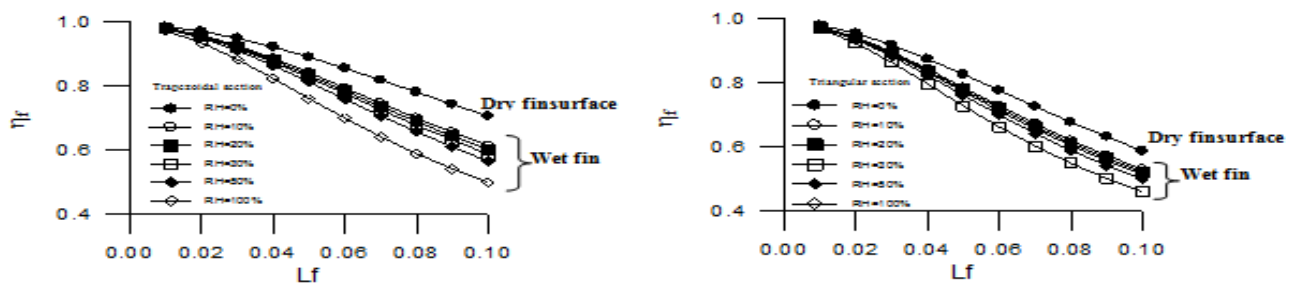

(a)
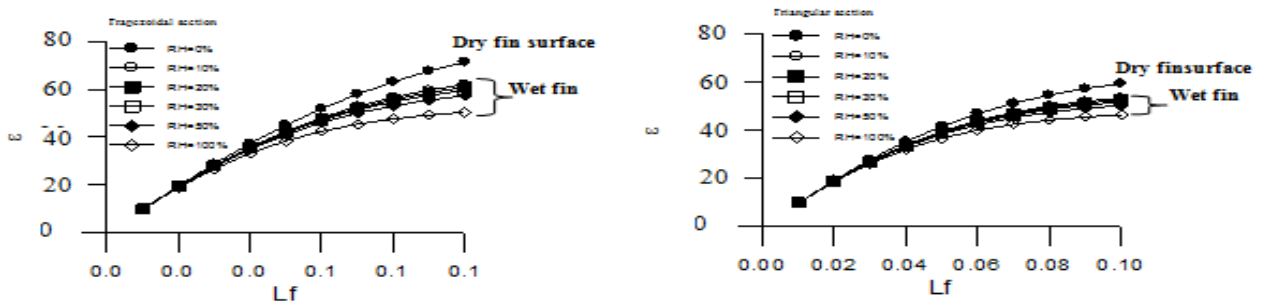

(b)

Figure 4: Effect of Fin Length on (a) Efficiency and (b) Effectiveness at Different Relative Humidity for Trapezoidal and Triangular Sections of Fin.
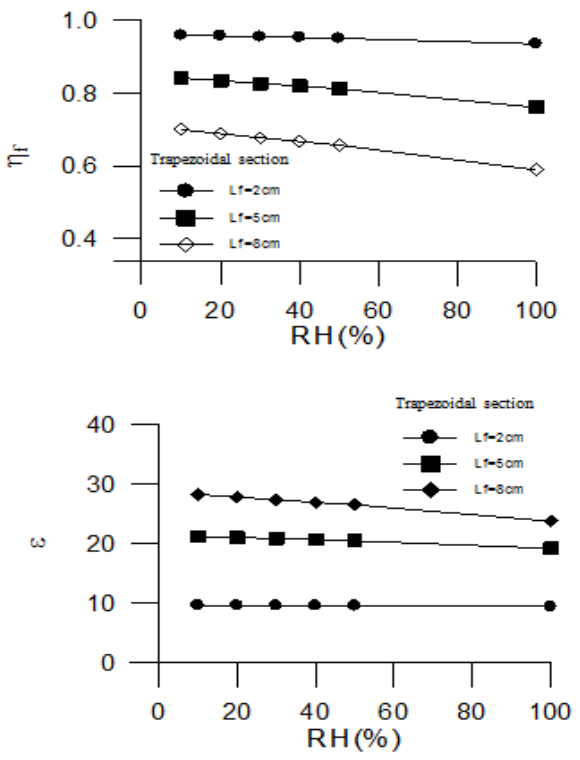

(a)
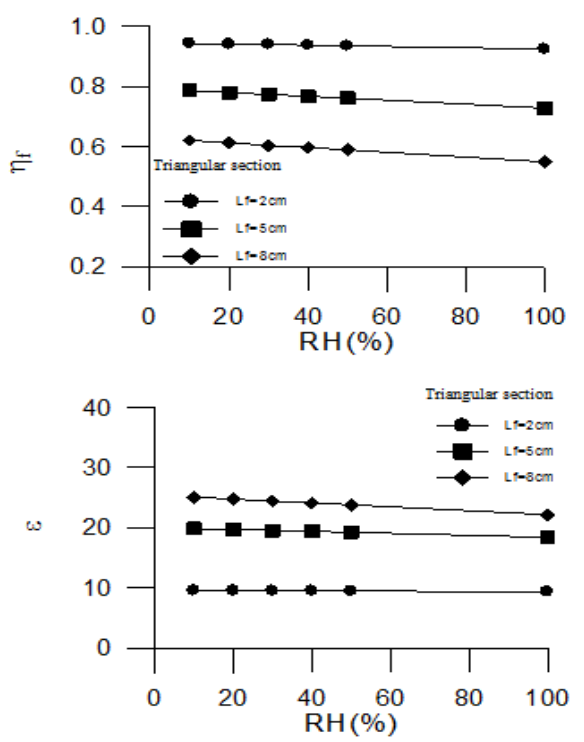

(b)

Figure 5: Effect of the Relative Humidity at Different Fin Length on (a) Fin Efficiency (b) Fin Effectiveness. 


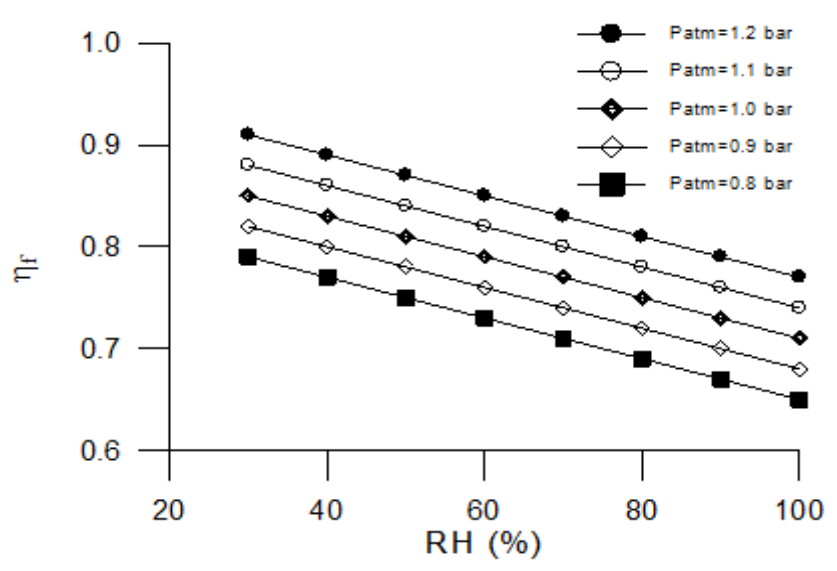

Figure 6: Effect of Relative Humidity on Fin Efficiency at Different Barometric Pressure.

\section{CONCLUSIONS}

This study is carried out for two types of longitudinal tapered fin (trapezoidal and triangular sections) exposed to wet air conditions in two-dimensions under fully wet air numerically using some assumptions. The study included two cases, wet and dry air conditions. General conclusions can be written as the following:

- The temperature gradient at the fin end for a wet fin is smaller than that of the dry fin and the temperature at the surface increased when the relative humidity is increased.

- In the fully wet fin case at the same fin length, the fin effectiveness and fin efficiency increases with decreases in the relative humidity.

- It's clear that the fin efficiency depends on the barometric pressure in the fully wet fin case, increases in the barometric pressure leads to increases in the efficiency of fin.

- Finally, the increases in the relative humidity cause increases in the heat transfer through the fin.

\section{REFERENCES}

1. L. Rosario, M. M. Rahman, "Overall Efficiency of a Radial Fin Assembly Under Dehumidifying Conditions", ASME, Journal of Energy Resources Technology120, (1998) 299-304.

2. G. Wu, T. Y. Bong, "Overall Efficiency of a Straight Fin with Combined Heat and Mass Transfer", ASHRAE Transactions 100 (1994) 367-374, part I.

3. S. Y. Liang, T. N. Wong, G. K. Nathan, "Comparison of One-Dimensional and Two-Dimensional Models for Wet-Surface Fin Efficiency of a Plate-Fin-Tube Heat Exchanger", Appl. Thermal Eng. 20 (2000) 941-962.

4. B. Kundu, "An Analytical Study of the Effect of Dehumidification of Air on the Performance and Optimization of Straight Tapered Fins", Int. Commun. Heat Mass Transfer 29 (2002) 269-278.

5. B. Kundu, P. K. Das, "Performance and Optimization Analysis for Fins of Straight Taper With Simultaneous Heat and Mass Transfer", Transaction of the ASME 126 (2004) 862-868.

6. P. Naphon, "Study on the Heat Transfer Characteristics of the Annular Fin Under Dry-Surface, Partially Wet-Surface, and Fully Wet-Surface Conditions", International Communications in Heat and Mass Transfer 33 (2006) 112-121. 
7. M. H. Sharqawy, S. M. Zubair, "Efficiency and Optimization of Longitudinal Fin with Combined Heat and Mass Transfer-an analytical solution", Int. J. Refrig. 30 (2007), 751-757.

8. M. H. Sharqawy, S. M. Zubair, "Combined Heat and Mass Transfer Analysis From Annular Fins of Constant Cross-Sectional Area", in: $8^{\text {th }}$ International Symposium on Advances in Computational Heat Transfer Proceedings, ICHMT, Marrakech, Morocco, Paper\# CHT-08-239, May 2008.

9. B. Kundu and D. Barman, "Analytical Study on Design Analysis of Annular Fins Under Dehumidifying Conditions with a Polynomial Relationship Between Humidity Ratio and Saturation Temperature", International Journal Heat and Fluid Flow, 2010.

10. Ziad, M. Almakhyoul," Heat Characteristics and Performance of Longitudinal Fin Exposed to Wet Air", Al-Rafidain Engineering Journal, Vol. 22, No.3, 2014. 